\title{
Critical appraisal of drug promotional literature using World Health Organisation guidelines
}

\author{
Sandhya Rani Gautam ${ }^{1}$, Preeta Kaur Chugh ${ }^{1 *}$, Ravinder Kr. Sah ${ }^{2}$, C. D. Tripathi ${ }^{1}$
}

\begin{abstract}
${ }^{1}$ Department of Pharmacology, Vardhaman Mahavir Medical College and Safdarjung Hospital, New Delhi, India ${ }^{2}$ Department of Pharmacology, Lady Hardinge Medical College, New Delhi, India

Received: 06 June 2017

Revised: 26 June 2017

Accepted: 30 June 2017

*Correspondence to:

Dr. Preeta Kaur Chugh, Email: docpreeta@yahoo.com

Copyright: (C) the author(s), publisher and licensee Medip Academy. This is an openaccess article distributed under the terms of the Creative Commons Attribution NonCommercial License, which permits unrestricted noncommercial use, distribution, and reproduction in any medium, provided the original work is properly cited.
\end{abstract}

\begin{abstract}
Background: Pharmaceutical marketing using drug promotional literatures is an important strategy adopted by the companies to promote their drugs. The primary objective of the present study is to compare the drug promotional literature of different pharmaceutical companies on the basis of World Health Organization (WHO) guidelines on ethical drug promotion.

Methods: This observational, cross sectional study was conducted at a tertiary care hospital, Delhi. The promotional literature was evaluated in accordance with WHO guidelines, nature of claims, pictorial content presented in it and for the cited references.

Results: A total of 208 promotional brochures were analysed. Only few (5.8\%) of the promotional literature fulfilled all the criteria as mentioned by the guidelines. Nutritional supplements $(27.9 \%)$ were the most promoted group of drugs. Pharmaceutical companies were most reluctant to provide information regarding contraindications $(9.6 \%)$, adjuvants (11.5), side effects $(10.6 \%)$ and drug interactions $(9.6 \%)$. Generic name, brand name, dosage form, therapeutic indications were outlined in most of the brochures. Exaggerated emotional claims were made in $47.1 \%$ brochures, followed by that of efficacy in $39.4 \%$ and safety in $25 \%$ of brochures. Pictures of medicinal products outnumbered others with $39.9 \%$ followed by pictures of women, children and doctors with $20.7 \%, 17.3 \%$ and $13.5 \%$ respectively.

Conclusions: Majority of the drug promotional literature did not comply with the ethical guidelines and was inadequate in terms of their adequacy, quality and reliability. Hence, it can be concluded that the majority of the promotional advertisements that are given to the prescribers are not able to spread awareness towards rational prescribing.
\end{abstract}

Keywords: Advertisement, Brochures, Drug promotional literature, WHO guidelines, Pharmaceutical company

\section{INTRODUCTION}

Pharmaceutical marketing is an important strategy adopted by the companies to promote their drugs. The World Health Organization (WHO) defines "promotion" as all informational and persuasive activities by manufacturers and distributors, the effect of which is to induce the prescription, supply, purchase and/or use of medicinal drugs. ${ }^{1,2}$ All promotion making claims concerning medicinal drugs should be reliable, accurate, truthful, informative, balanced, up-to-date, and capable of substantiation. They should not contain any misleading or unverifiable statements or omissions likely to induce medically unjustifiable drug use or to give rise to undue risks. $^{1}$

Drug advertisement using promotional literature is a persuasive communication and forms an integral part of pharmaceutical marketing. Drug promotional literature (DPL) includes product characteristics, side effects, dosage regime, contraindications and various marketing claims with references which at times, may be inadequate, deceptive and of poor educational value. These lapses in the field of ethics are a matter of immense concern for the past few decades. DPL provided by the pharmaceutical companies cannot be entirely relied upon for being disseminating drug information for their own interest, still 
they tends to have a powerful impact on physicians prescribing behaviour. ${ }^{3}$ Various studies have demonstrated that printed drug promotional materials distributed by the pharmaceutical companies are often biased. ${ }^{4,5}$ Lack of time to access medical literature further complicate the way in to impartial drug information in developing countries. ${ }^{6}$

In today's era, with the discovery of newer generations of therapeutic agents, prescribing physicians need to keep themselves updated with the ever changing scientific knowledge of medicines. Various claims have been quoted in the drug promotional advertisements and references are also provided to increase their credibility and authenticity. However, a grey zone has always been there for manipulation by the pharmaceutical industry because of the dearth of standard recommendations for it in India. It is essential to sensitize the medical fraternity and educate them regarding the harmful nature of unethical drug promotion. They should be trained to critically analyse drug advertisements and other promotional materials. We believe these initiatives could be quite helpful to sensitize the future prescribers on drug promotion.

This study aims to create awareness of the credibility, reliability and authenticity of the drug promotional literature among the prescribers, which are tactically given to them by the medical representatives. With this background, the present study was conducted with the primary objectives of comparing the drug promotional literature of different pharmaceutical companies on the basis of WHO guidelines on ethical drug promotion.

\section{METHODS}

The present study was conducted to critically appraise the accuracy and ethical status of DPL distributed to prescribing physicians by using "WHO criteria for ethical medicinal drug promotion, 1988". We also evaluated the drug promotional brochures for the type of claims and pictorial content presented in it and the number of references quoted in support of the claims.

This observational, cross-sectional study was conducted in the Department of Pharmacology, Vardhman Mahavir Medical College and Safdarjung Hospital New Delhi, India, after its approval by the Institutional Ethics Committee. Approximately 323 leave behind brochures were collected randomly from various outpatient departments, namely medicine, surgery, psychiatry, obstetrics and gynaecology, ophthalmology, skin, paediatrics, and orthopaedics. Literature promoting medicinal devices and equipment's, orthopaedic prosthesis, ayurvedic medicines, drug monographs, reminder advertisements and drugs name list were excluded from the study.

WHO criteria for ethical medicinal drug promotion dictate that promotional literature should contain following information. ${ }^{1}$
- $\quad$ The name(s) of the active ingredient(s) using either international nonproprietary names (INN) or the approved generic name of the drug;

- $\quad$ The brand name;

- Amount of active ingredient(s) per dose;

- Other ingredients known to cause problems, i.e. adjuvant;

- $\quad$ Approved therapeutic uses;

- Dosage form or dosage schedule;

- Safety information including side effects and major adverse drug reactions;

- Precautions, contraindications and warnings;

- Major drug interactions;

- Name and address of manufacturer or distributor;

- Reference to scientific literature as appropriate.

In addition to this information, DPLs were evaluated for various claims about the medicinal product. Claims were classified into seven categories as efficacy, safety, cost, convenience, pharmacokinetic property, pharmaceutical property and exaggerated emotional claims. Number of references quoted in support of the claims made in the promotional literature was further evaluated.

Numerous pictures have been used by the pharmaceutical companies to make the DPLs more attractive and to influence doctors for prescribing the drug promoted in it. Pictorial content of the promotional brochures was evaluated for the type of pictures (men, women, elderly, children, doctors, medicinal products, or other treatment unrelated pictures) and number of scientific Figures.

\section{RESULTS}

A total of 323 drug promotional brochures were collected from the outpatient department of our hospital, out of which 208 were included in the study and 115 (reminder cards, drug list, brochures promoting equipment, orthopaedic prosthesis) were excluded from the study.

\section{Type of drug}

The therapeutic classification of the drugs promoted in the promotional material is represented in Figure 1. Out of 208 promoted drugs, $94(45.2 \%)$ were fixed dose combinations (FDCs) whereas $114 \quad(54.8 \%)$ were single drug preparations. Nutritional supplements $(27.9 \%)$ were the most promoted group of drugs followed by cardiovascular drugs $(14.4 \%)$. Non-steroidal anti-inflammatory drugs (13.5\%), gastrointestinal drugs (12.5\%) and chemotherapeutic agents $(11.5 \%)$ come quite close with third and fourth and fifth position amongst the promoted drugs.

\section{Fulfilment of WHO criteria}

We observed that only $5.8 \%$ of the brochures fulfilled all the criteria's laid down by WHO, the ethical guidelines for drug promotion. Pharmaceutical marketing was primarily 
focused on highlighting the strengths of the drug or formulation and were most reluctant to provide information regarding contraindications (9.6\%) and adjuvants (11.5). Likewise information regarding side effects and drug interactions were outlined in only $10.6 \%$ and $9.6 \%$ of brochures respectively. It was found that most of the evaluated brochures were satisfying only six criteria, namely brand name $(100 \%)$, INN $(95.2 \%)$, content of the active ingredients (90.4\%), dosage form (92.3\%), approved therapeutic uses $(93.2 \%)$, and address of the manufacturer $(87.5 \%)$ as shown in Figure 1. However, only $31.7 \%$ of the promotional materials had statements supported by cited references. To conclude, the therapeutic information provided in the promotional literature was not found to be sufficient for the prescriber to make a rational decision to use the promoted drug.

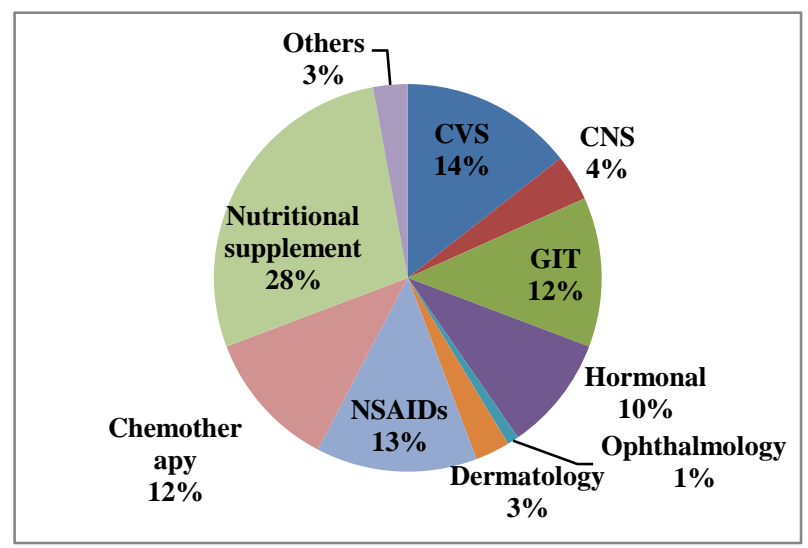

Figure 1: Therapeutic classification as per type of drug promoted in the literature.

\section{Claims}

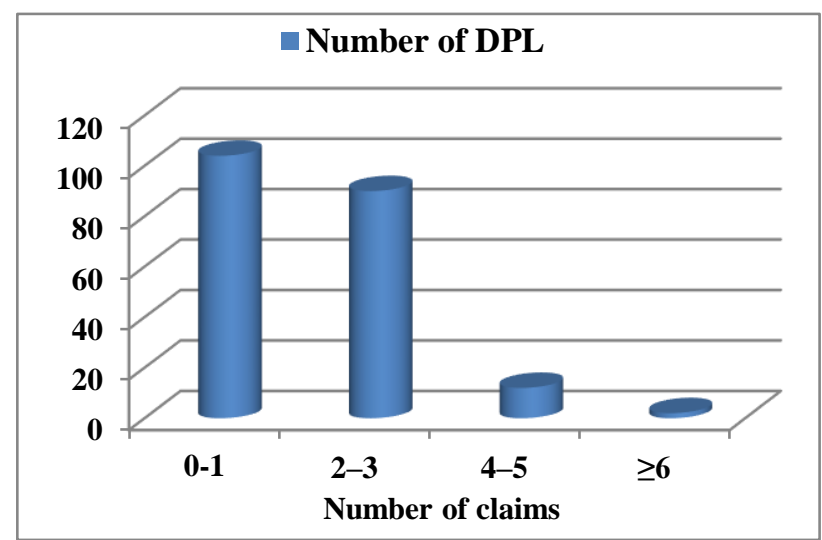

Figure 2: Variation in number of claims per advertisement.

In addition to the desired therapeutic information, pharmaceutical industry made multiple claims regarding the product as much as 6 per brochure, as seen in majority of the drug promotional brochures (Figure 2). A total of 339 claims were made in 208 DPLs evaluated. Exaggerated emotional claims about the promotional drug were made in $98(47.1 \%)$ brochures, followed by that of efficacy in $82(39.4 \%)$ and safety stood at third position with $52(25 \%)$ as depicted in Figure 3. Number of promotional brochures making claims regarding cost effectiveness, convenience, pharmacokinetic properties and pharmacodynamics properties were 28 (13.5\%), 48 $(23.1 \%), 13(6.2 \%)$ and $18(8.6 \%)$ respectively.

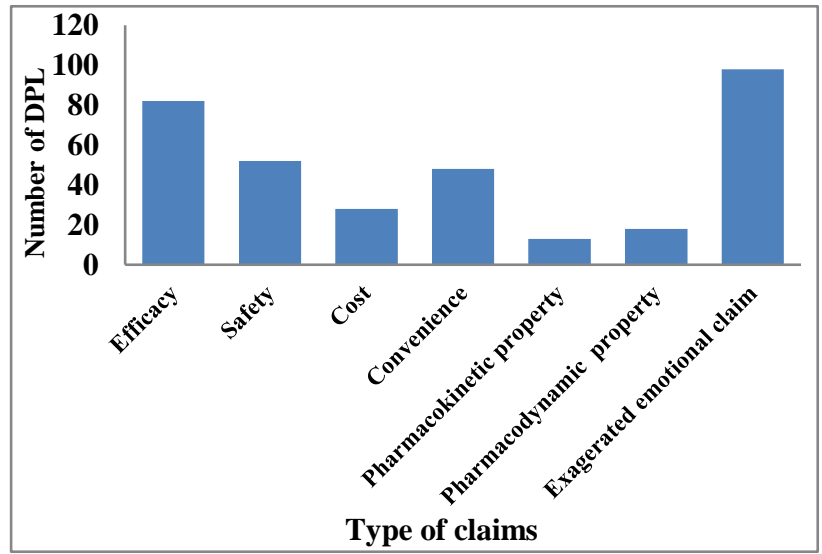

Figure 3: Type of claims made in the drug promotional literature.

Pharmaceutical industries gave references in support of claims mentioned in the DPLs. But many of the claims made by them were not supported with data. Only 154 references were cited for 339 claims made in the evaluated brochures. Approximately two-third of promotional brochures $(69.2 \%)$ didn't cite any reference for the mentioned claims. References in the range of two to eight per brochures were given by only $15.4 \%$ of the DPLs. Classification of references distinctly demonstrates that citations from journal articles $(79.2 \%)$ were the maximum in number followed by web citations, databases and books.

\section{Pictures}

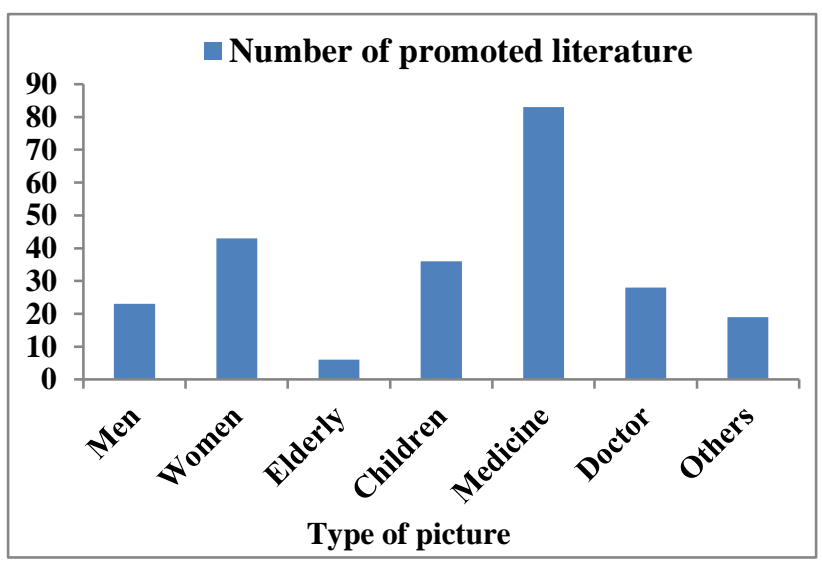

Figure 4: Types of pictures depicted in promotional literature.

These promotional brochures were made striking using various types of pictures and devoting a major area of the 
DPLs to them. It was type of picture and not the number of pictures per brochure, which we counted while evaluating the literature as shown in Figure 4. Our findings demonstrated that $66.3 \%$ of brochures contained numerous pictures to promote their drug. The pictures were also eyecatching and flashy. Pictures of medicinal products outnumbered others with $39.9 \%$ followed by pictures of women, children and doctors with $20.7 \%, 17.3 \%$ and $13.5 \%$ respectively.

\section{DISCUSSION}

Drug promotional literatures are used as a promotional tool to advertise new drugs entering the market. It is crucial for the prescribing physicians to critically analyse the risk benefit ratio of drugs provided in drug promotional literature in order to determine the most appropriate and rational treatment for the patients. Clinicians need to keep themselves well informed and updated about the hundreds of new drugs entering the market every year. There is an urgent need to draw the inference and respond to the pharmaceutical promotional tactics and pressures in a much more responsible and diligent manner.

The drug promotional activities of pharmaceutical industries are regulated by "World Health Organization criteria for ethical medicinal drug promotion, 1988 ". ${ }^{1}$ It is thought to be the foundation of self-regulatory code of Organization of Pharmaceutical Producers of India (OPPI). ${ }^{7}$ We can check the rationality of DPL by evaluating them on these criteria. The main objective of ethical criteria for medicinal drug promotion is to support and encourage the improvement of health care through the rational use of medicinal drugs. ${ }^{1}$ Regional ethics committees collect complaints against unethical drug promotion and forward them to drug controller authorities to take imperative steps to regulate guilty companies. ${ }^{8,9}$ But, the bitter truth is that most of the information disseminated through drug advertisements is inconsistent with the code of ethics. Hence, government regulatory bodies have to take a strict initiative to discipline any lack of compliance with the ethical code and should ensure that none case will go unreported.

Our study aimed to evaluate the ethical standards of DPLs in accordance to WHO guidelines. It was observed that very few of the drug promotional materials contained all of the essential information recommended by the WHO's Ethical Criteria for Medicinal Drug Promotion. Similar line of findings was reported from various other studies. $^{10-14}$

The pharmaceutical industries rather accomplish their own commercial motive and neglected the ethical educational aspect. This carries a marked impact on the overall health delivery system. In our study it was observed that the therapeutic class of drug that were promoted the most are nutritional supplements which is in line with a similar study conducted in Malaysia. ${ }^{15}$ Concerns arising with the promotion of this class of drugs include a tendency for self-medication which further raises the concern for toxicities. It is known that unsupervised intake of nutritional supplements could result in adverse effects/toxicity. ${ }^{16,17}$ Thus, it is recommended that nutritional supplements should only be used with strong medical indication, such as symptomatic nutrient deficiency disease. Our findings suggest that majority of the DPLs mentioned INN $(95.2 \%)$, brand name (100\%), therapeutic indication (93.2\%), amount of active ingredients (90.4\%) and dosage forms (92.3\%). These findings are in line with few similar studies conducted in a tertiary care hospital..$^{8,10,12,18-20}$

Another striking finding is that the essential information regarding adverse effects contraindications, drug interactions were reported to be present in only one tenth of the drug promotional literature in our study. This indicates that the companies are less focussing on providing essential information regarding the safety of the patients. Similar observations on omission of these important criteria's were reported from previous studies also. ${ }^{10,12}$

The promotional drug advertisements were full of unsubstantiated claims and most of those claims were therapeutically inaccurate and not based on proper scientific evidences. This unethical advertisement of drugs highlighting the positives, built misconceptions and encourages drug consumerism and contributing to irrational drug use through inappropriate prescribing. ${ }^{5}$ Several claims regarding efficacy, safety, convenience, pharmacokinetic property and cost were observed to be quite common in our study which are in line with the findings of a similar study conducted by Mali et al in a tertiary care hospital. ${ }^{10} \mathrm{~A}$ total of 339 claims were made in our study ranging from 1-6 per DPL. Another important criterion for unbiased DPL is appropriate referencing of the information cited in the scientific literature. However, only $31.7 \%$ of the literature in DPL is supported by references in our study. Another study has reported that as high as $40 \%$ of information in the promotional material was not referenced and approximately $22 \%$ references were irrevocable. ${ }^{10}$ In view of this study, it becomes essential for the prescribing physician to judiciously assess the drug promotional literature on the established guidelines and also ensure its validity and authenticity before accepting them as scientific piece of information. This assumes even greater importance as unjustified use of such therapeutic agents may result in failure of therapy or serious toxicities. ${ }^{21}$

Therapeutically irrelevant information was printed in the form of various pictures, compromising space that would have been used to cite more relevant scientific information. In our study we assess the type of pictures presented in the collected DPLs and our findings suggest that $66.3 \%$ of the brochures contain various pictures to promote their products which are in line with the findings of a similar study. ${ }^{22}$ Pictures of medicinal products were forming the largest category in varied types of pictures 
presented in the evaluated brochures as shown in figure 4. Similar observation was reported from a study conducted by Ganashree $\mathrm{P}$ et al. ${ }^{23}$ A total of 208 DPLs contained 14 $(6.7 \%)$ Figures and $4(1.9 \%)$ to depict the data on the promotional drugs. Quality of paper, print, and colour were excellent in all DPL.

We need to encourage our doctors to acquire knowledge of the art of critical appraisal of DPL possibly during their undergraduate training. This would compel them to look up to the authentic medical literature for reference and to be cautious not to rely solely on these DPLs. Furthermore, evidence supports the importance of physician mediated knowledge translation, as people report higher rates of intention to use medications when they have been informed of the benefits by their physician. ${ }^{24,25}$ Incorporation of such less explored areas in the undergraduate teaching curriculum shall definitely help to sensitize them. Furthermore, interventional educational research, workshops and training programmes among the undergraduates about the ethical drug promotion are the highly suggested ways to improve the knowledge and awareness regarding the same.

\section{CONCLUSION}

Majority of the drug promotional literature analysed in our study did not comply with the ethical guidelines and was inadequate in terms of their adequacy, quality and genuineness of coverage. Hence, it can be concluded that the majority of the promotional advertisements that are given to the prescribers are not able to spread awareness towards rational prescribing. Training programmes and sensitization in early years of undergraduate teaching modules might bring about improvement in the field of ethical medicinal promotion.

Funding: No funding sources Conflict of interest: None declared

Ethical approval: The study was approved by the Institutional Ethics Committee

\section{REFERENCES}

1. Ethical criteria for medicinal drug promotion. World Health Organization [Online]. 1988 May 13. Available at: http://apps.who.int/medicinedocs/documents/whozip 08e/whozip08e.pdf (last assessed on 10th may 2017).

2. Sahne BJ, Yegenoglu S, Uner M, Wertheimer AI. Adherence of drug advertisements to the international marketing codes. Hacettepe University Journal of the Faculty of Pharmacy. 2012;32(1):53-6.

3. Chitnis K, Limaye A, Bhosale M. Pharmaceutical promotional literature: Opinions of physicians in a tertiary care hospital in Mumbai. Int $\mathrm{J}$ Basic Clin Pharmacol. 2013;2:541-7.

4. Mastroianni PC, Noto AR, Galduróz JC. Psychoactive drug advertising: analysis of scientific information. Rev Saude Publica. 2008;42(3):529-35.
5. Randhawa GK, Singh NR, Rai J, Kaur G, Kashyap R. A critical analysis of claims and their authenticity in Indian drug promotional advertisements. Adv Med. 2015;469147.

6. Subish P, Mishra P, Shankar PR, Bista D, Purwar B. Contribution of the regional drug information center towards drug safety-an experience from Western Nepal. J Nep Med Assoc. 2006;45:216-8.

7. Draft OPPI Code of Pharmaceutical Practices. 2012. Available at: http://www.ifpma.org/fileadmin/content/About\%20us /2\%20Members/Associations/Code-India/OPPI Code of Pharmaceutical Practices2012.pdf.

8. Garje YA, Ghodke BV, Lalan HN, Senpaty S, Kumar R, Solunke S. Assessment of Promotional Drug Literature Using World Health organisation (WHO) Guidelines. Indian Journal of Applied Research. 2014;4(2):2249-351.

9. Vlassov V, Mansfield P, Lexchin J, Vlassova A. Do drug advertisements in Russian medical journals provide essential information for safe prescribing? West J Med. 2001;174:391-4.

10. Mali SN, Dudhgaonkar S, Bachewar NP. Evaluation of rationality of promotional drug literature using World Health Organization guidelines. Indian J Pharmacol. 2010;42:267-72.

11. Khakhkhar T, Mehta M, Sharma D. Evaluation of drug promotional literatures using WHO guidelines. J Pharm Negative Results. 2013;4:33-8.

12. Alam K, Shah AK, Ojha P, Palaian S, Shankar PR. Evaluation of drug promotional materials in a hospital setting in Nepal. Southern Med Review. 2009;2(1):26.

13. Phoolgen S, Kumar SA, Kumar RJ. Evaluation of the rationality of psychotropic drug promotional literatures in Nepal. J Drug Discov Ther. 2012;2:6-8.

14. Jadav SS, Dumatar CB, Dikshit RK. Drug promotional literatures (DPLs) evaluation as per World Health Organisation (WHO) criteria. J App Pharm Sci. 2014;4:84-8.

15. Patil A, Kale SB. Evaluation of Rationality of Drug Promotional Literature in Malaysia Using Local and International Guidelines. American Journal of PharmTech Research. 2015;5(5):264-72.

16. Lhamo Y, Chugh PK, Tripathi.CD. Vitamin D Supplements in the Indian Market. Indian J Pharm Sci. 2016;78(1):41-7,54.

17. Chugh PK, Lhamo Y. An assessment of vitamin supplements in the Indian market. Indian J Pharm Sci. 2012;74:469-73.

18. Jain VK, Kaore SN, Amane HS, Jain M, Katakwar M, Thawani V. Evaluation of rationality of printed promotional medicine literature. Int $\mathbf{J}$ Health Allied Sci. 2016;5:45-9.

19. Tayade MC, Kulkarni NB. Accuracy of the drug advertisements in medical journals in India. J Clin Diagn Res. 2011;5:583-5.

20. Charan J, Yadav P, Saxena D, Kantharia ND. Drug advertisements published in Indian Medical Journals: 
Are they ethical? J Pharm Bioallied Sci. 2011;3:4036.

21. Gore R, Chugh PK, Tripathi CD, Lhamo Y, Gautam S. Pediatric off-label and unlicensed drug use and its implications. Curr Clin Pharmacol. 2017 Mar 17.

22. Mikhael EM. Evaluating the reliability and accuracy of the promotional brochures for the generic pharmaceutical companies in Iraq using World Health Organization guidelines. Journal of Pharmacy and Bioallied Sciences. 2015;7(1):65-8.

23. Ganashree P, Bhuvana K, Sarala N. Critical review of drug promotional literature using the World Health Organization guidelines. Journal of Research in Pharmacy Practice. 2016;5(3):162-5.

24. Lhamo Y, Chugh PK, Gautam SR, Tripathi CD. Epidemic of Vitamin D Deficiency and Its
Management: Awareness among Indian Medical Undergraduates. Journal of Environmental and Public Health. 2017:2517207.

25. Engels Y, Assema PV, Dorant E, Lechner L. Factors associated with the intention to use vitamin D supplements: quantitative study among a sample of elderly people in a medium-sized town in the Netherlands. Journal of Nutrition Education and Behaviour. 2001;33(3):134-42.

Cite this article as: Rani SG, Chugh PK, Sah RK, Tripathi CD. Critical appraisal of drug promotional literature using World Health Organisation guidelines. Int J Basic Clin Pharmacol 2017;6:20149. 